\title{
MULTILETRAMENTOS NA ESCOLA E O PIBID LETRAS-INGLÊS DA UFES
}

\author{
Stefany Pinto Rogério ${ }^{1}$
}

\begin{abstract}
Resumo: Ao pensarmos na educação pública brasileira, é natural que pensemos tanto nas escolas regulares, quanto nas Universidades públicas. Porém, essas instituições coexistem em nossa sociedade de forma distante. Enquanto muitos professores universitários da licenciatura afirmam terem tido pouquíssimo contato com o ensino básico, muitos licenciandos em LetrasInglês não se imaginam assumindo o papel de professores no futuro, especialmente no ensino público. O Pibid - Programa Institucional de Bolsas de Iniciação à Docência - proporciona diálogo entre universidade e escola pública, e tem mostrado como a relação entre ensino básico e superior pode ser mais próxima. Este artigo, originado de uma pesquisa de Iniciação Científica (PRPPG - Ufes edital 2019-2020), apresenta uma análise feita por meio de entrevistas com exparticipantes do Pibid Letras Inglês da Universidade Federal do Espírito Santo sobre possíveis formas de como a graduação de Licenciatura em Inglês pode melhorar com a experiência do programa, reiterando a importância deste para a formação docente, e, consequentemente, para o benefício da sociedade. Dentro desse contexto, analisa-se também a construção da identidade do professor de Inglês pelo Pibid e a presença dos multiletramentos nas práticas realizadas no programa. Os resultados obtidos apontam para a potência deste na formação dos licenciandos de Letras-Inglês da Ufes.
\end{abstract}

Palavras-chave: Pibid. Ensino de Língua Inglesa. Ensino público. Identidade. Multiletramentos.

\begin{abstract}
When thinking about public education in Brazil, it is natural to think about both regular schools and public universities. However, these institutions coexist distantly in our society. While many university professors in undergraduate courses claim to have had very little contact with basic education, many English undergraduate students cannot imagine taking on the role of teachers in the future, especially within public education. The Pibid - Institutional Program for Teaching Initiation Scholarships - provides dialogue between the university and public schools, and has shown how the relationship between basic and higher education could be closer. This article, originated from a Scientific Initiation research (PRPPG-Ufes 2019-2020) based on interviews with former participants of the Federal University of Espírito Santo LetrasInglês Pibid, presents an analysis of how the undergraduate course in English can improve with this program experiences, reiterating its importance for the education of future professionals and, consequently, for the benefit of society. Within this context, the construction of the English language teacher identity through Pibid and the presence of multiliteracies in the practices
\end{abstract}

\footnotetext{
${ }^{1}$ Graduada em Língua Inglesa e Literatura de Língua Inglesa pelo departamento de Línguas e Letras da Universidade Federal do Espírito Santo (Ufes). Vitória, Espírito Santo, Brasil. E-mail: prstefany@gmail.com.
} 
carried out in the program are also analyzed. The results obtained point to the strength of such program in the formative process of undergraduate students of Letras-Inglês at Ufes.

Keywords: Pibid. English Language Teaching. Public school. Identity. Multiliteracies.

\section{Introdução}

Nos últimos anos, os cursos superiores formadores de professores têm se atualizado de forma a adaptar antigos e novos saberes ao mundo globalizado em que vivemos hoje. Cada vez mais fala-se sobre letramento crítico, cidadania ativa, agência e sobre novas perspectivas de ensino. Ao mesmo tempo, no entanto, ainda existe certo distanciamento entre a escola básica e as universidades que formam professores para elas, o que muitas vezes acaba por fortalecer a dicotomia teoria x prática para os alunos da licenciatura.

O Pibid - Programa Institucional de Bolsas de Iniciação à Docência - é um programa responsável por aproximar alunos da graduação em licenciatura da atividade docente desde os semestres iniciais de sua formação. Nele, bolsistas e voluntários têm a oportunidade de frequentarem, conhecerem e atuarem no ambiente escolar público, com a supervisão de coordenadores atuantes na universidade e professores-supervisores na escola. Experiências docentes como essa não apenas são importantes para o processo de formação de futuros professores, como de fato são necessárias, pois, embora os currículos de licenciatura possuam hoje mais disciplinas direcionadas ao ensino desde seu início, como é o caso do curso de licenciatura em Língua e Literatura Inglesa da Ufes (PPC 2006), as experiências de estágio obrigatório, que permitem contato mais direto com a escola básica, de modo geral, só têm lugar nos períodos finais da graduação.

Diante disso, muitos alunos da licenciatura de Inglês resistem em atuar como professores de ensino básico, pois ao se depararem com a complexidade da escola pública e sem conhecer verdadeiramente seus meandros e possibilidades, preferem buscar caminhos alternativos e menos complexos. Os preconceitos disseminados sobre o ofício - de que os alunos não se interessam por estudar, de que os salários são péssimos, de que há muitos alunos por turma, etc. - fazem com que os graduandos revejam sua disponibilidade e seu desejo de trabalharem em escolas regulares. Essa visão negativa da docência se intensifica quando se fala da escola pública. Especialmente quando falamos da licenciatura em Língua e Literatura Inglesa, há dois grandes problemas; o primeiro é o mito de que, como observado por Paiva (1997, p. 12) “a escola secundária, especialmente a pública, não é competente para ensinar 
línguas estrangeiras". Essa visão discutida pela autora, compartilhada por outros autores e acadêmicos brasileiros, é o que se conhece por discurso do fracasso (FORTES, 2017). O segundo problema é que, sendo professores de Inglês, buscar outros caminhos parece muito mais fácil, pois há cursos de idiomas privados por toda parte. Ainda é difícil, para muitos, pensar na possibilidade de uma prática diferente do ensino de língua inglesa (ou LI) - menos estruturalista, mais crítica e voltada à realidade dos alunos - na escola pública.

Através das práticas e experiências vivenciadas no Pibid, diversos preconceitos sobre o trabalho do professor e o funcionamento da escola pública são repensados pelos graduandos ainda durante a graduação e não somente ao final dela, de modo que os universitários participantes do programa se sintam mais preparados e entendam que a docência é uma carreira viável, embora complexa, e que a maneira como é exercida tem impactos valiosos na sociedade. Simultaneamente, escolas públicas participantes do projeto também passam a entender a presença da universidade não mais de forma vigilante e crítica do que nela acontece, mas com sua real intenção: uma legítima troca de saberes onde, em termos de experiência, a escola tem muito mais a oferecer aos graduandos do que o oposto. Desse modo, o distanciamento entre escola e universidade (AMBROSETTI et al., 2013) é, aos poucos, reduzido.

A experiência de vivenciar o universo escolar de forma tão próxima e ativa quanto o programa permite que se faça, e não só através de discussões na faculdade, proporciona um salto na evolução profissional e identitária dos futuros professores, uma vez que, como observa Pimenta (1999, p. 27) “Os saberes pedagógicos podem colaborar com a prática. Sobretudo se forem mobilizados a partir dos problemas que a prática coloca, entendendo, pois, a dependência da teoria em relação à prática, pois esta lhe é anterior".

A identidade do professor de língua inglesa (CUNHA; MOREIRA, 2008) e seu processo subjetificador (FORTES, 2017) - aqui entendidos, respectivamente, como a forma como nos encaixamos na sociedade e o processo pelo qual nos tornamos indivíduos singulares - são discussões geralmente vistas como de menor importância nas práticas da graduação, mas podem, assim, ressignificar-se, ao passo que o próprio graduando compreende melhor quem ele é como pessoa e como professor por meio das interações mediadas pelo Pibid. Entende-se também que os professores de Inglês não precisam ou devem se ater a um ensino vazio de gramática, o famoso "verbo to be" que, desacompanhado de um contexto que tenha significado, pouca relevância tem para os alunos do ensino básico. Citando Fortes, 
PERcursos Linguísticos • Vitória (ES) •v. 11 •n. 27 • 2021 • ISSN: 2236-2592・

Dossiê: Pibid e RP na formação de professores de letras •

[S]e pensarmos no aprendizado de LI no mundo contemporâneo, e em seu potencial educacional e cultural, político e ideológico, vemos que o ensino de inglês na escola básica precisa passar por ressignificações do que pode realmente ser 'relevante' e/ou de interesse para quem o aprende. (FORTES, 2017, p. 92)

Entender isso também contribui para a formação dos professores de língua inglesa e para a melhoria do ensino de inglês da escola pública, na qual um dia poderão atuar.

Essa possibilidade de trabalhar assuntos realmente relevantes através da aula de Inglês ganha espaço por meio das teorias e práticas dos multiletramentos e do letramento crítico. A prática do letramento crítico em sala, como dito por Duboc e Ferraz (2011, p. 22), “consiste no exercício de construção de sentidos nas dimensões individual, comunitária e global, de forma a relacioná-las e, sobretudo, compreendê-las em suas semelhanças e diferenças". Já o conceito dos multiletramentos, para Moura e Rojo (2012, p. 13), aponta para dois tipos de multiplicidade presentes em nossas sociedades: "a multiplicidade cultural das populações e a multiplicidade semiótica de constituição dos textos por meio dos quais ela se informa e se comunica". O primeiro passo para que o ensino básico público acompanhe essas mudanças é que os cursos de licenciatura também o façam, e já o tem feito; e o exercício dessa prática através do Pibid de Letras-Inglês da Ufes tem se mostrado possível.

Tendo em vista esse contexto, desenvolvi entre os anos de 2019 e 2020, sob orientação da professora doutora Lívia Fortes - na época, uma das coordenadoras do Pibid Letras-Inglês da Ufes - uma pesquisa de Iniciação Científica de caráter qualitativo (BOGDAN; BIKLEN, 1982), que buscou compreender e mostrar de que maneira o citado programa influi na formação dos futuros professores de LI. Os dados obtidos neste estudo, por meio de entrevistas junto a três bolsistas do programa dos anos de 2018-2019, foram analisados em diálogo com o material teórico que o fundamenta.

O presente artigo apresenta um relato da investigação descrita acima, discutindo, a partir das falas dos três pibidianos, o impacto do Pibid em seu processo formativo e na relação destes com a profissão de professor. Desse modo, também é possível compreender melhor a influência do programa no processo de subjetificação e constituição identitária do aluno da licenciatura de língua inglesa da Ufes, e quiçá, de outras instituições e núcleos que tenham sido contemplados com o programa em sub-projetos relacionados às áreas de Linguagens, Códigos e Línguas Estrangeiras. 
PERcursos Linguísticos • Vitória (ES) •v. 11 •n. 27 • 2021 • ISSN: 2236-2592 •

Dossiê: Pibid e RP na formação de professores de letras •

No Pibid Letras-Inglês da Ufes, edital de 2018, as tarefas se dividiam entre idas semanais às escolas, produção de diários de campo, nos quais os pibidianos faziam reflexões sobre suas experiências no ambiente escolar, leituras e encontros quinzenais na universidade junto às coordenadoras do subprojeto de Língua Inglesa. Nesses encontros era possível discutir as vivências nas escolas, falar sobre os materiais lidos e fazer planejamentos que acompanhassem as propostas e demandas dos professores supervisores. A partir do subprojeto de Inglês, sempre houve a intenção de que as tarefas e projetos desenvolvidos pelos bolsistas nas escolas apresentassem uma perspectiva de fato significativa do ensino de Inglês, que trabalhassem o senso crítico, a consciência social, alinhando tais propósitos ao conteúdo previsto nos calendários escolares. Três escolas receberam os pibidianos de Letras-Inglês no ano de 2018, sendo estas localizadas em três grandes cidades do Espírito Santo: Vila Velha, Vitória e Serra. Os dados aqui analisados e discutidos foram gerados junto a bolsistas atuantes em escolas de dois desses três municípios, tendo tido supervisores diferentes em cada uma delas. A próxima seção descreve os procedimentos e instrumentos utilizados na geração dos dados que, mais adiante, serão debatidos.

\section{Metodologia}

A pesquisa apresentada neste artigo é de natureza qualitativa e interpretativa (BOGDAN; BIKLEN, 1982), uma vez que seu foco incide na compreensão das diferentes maneiras como a participação no programa Pibid (edital 2018-2019) influenciou a formação de alguns dos licenciandos de Letras Inglês da Ufes. A pesquisa também se preocupou em discutir a presença dos multiletramentos nas práticas desses universitários nas salas de aula das escolas que frequentaram. Os dados coletados foram analisados e interpretados com base no referencial teórico selecionado.

A primeira etapa do estudo consistiu em uma revisão da literatura no que diz respeito aos principais temas nele abordados, seguido da elaboração de um questionário inicial de quatro perguntas, que eram: 1) Como o Pibid mudou sua compreensão acerca da docência de língua inglesa? Escreva um relato sobre como o Pibid fez isso.; 2) Como você se percebe hoje, após a experiência do Pibid, enquanto futuro professor licenciado em língua inglesa?; 3) Como você acredita que a Universidade pode aprender com as experiências do Pibid?, e 4) Qual a sua visão 
PERcursos Linguísticos • Vitória (ES) •v. 11 •n. 27 • 2021 • ISSN: 2236-2592 •

Dossiê: Pibid e RP na formação de professores de letras •

da escola pública depois de ter passado pelo Pibid? As questões tinham como foco a experiência docente proporcionada pelo Pibid e seu impacto na relação licenciando x escola. Três voluntários, ex-bolsistas pibidianos, foram escolhidos ao acaso para responder essas perguntas, sendo duas delas (doravante referidas como pibidianas $\mathrm{Y}$ e Z) estagiárias em uma mesma escola, e o terceiro (doravante referido como pibidiano $\mathrm{X}$ ) atuante em outra. As entrevistas foram realizadas de forma escrita, através de um arquivo das perguntas compartilhado individualmente com cada um dos entrevistados via Google Docs, e as respostas foram analisadas posteriormente, com base no material bibliográfico.

A partir dos dados obtidos nas primeiras entrevistas, mais duas perguntas foram elaboradas; dessa vez, com foco na presença dos multiletramentos durante a experiência no Pibid, um assunto que ainda não havia sido especificamente questionado na primeira geração de dados. As perguntas eram respectivamente: 1) Os multiletramentos estiveram presentes nas suas práticas como estagiário do Pibid? Se sim, dê o exemplo de um momento., e 2) De que forma a prática dos multiletramentos tornou a experiência em sala de aula - sua, dos alunos diferente? Essas perguntas foram feitas em uma segunda etapa de entrevistas com os mesmos pibidianos.

É relevante deixar registrado que a segunda fase de entrevistas aconteceu após a declaração de quarentena devido à pandemia da COVID-19, o que impossibilitou a participação de uma das bolsistas inicialmente entrevistadas na segunda etapa de entrevistas devido a problemas pessoais relacionados a tal situação.

\section{Os entrevistados: sujeitos com identidades}

Dos três pibidianos entrevistados para a pesquisa, um deles, $\mathrm{X}$, atuava no município de Vila Velha, enquanto Y e Z atuavam em Vitória, em uma mesma escola. Sendo todos eles exalunos de escolas públicas do Espírito Santo, todos possuíam em sua própria trajetória uma relação com o ensino público. Esse detalhe é de grande relevância quando falamos da subjetificação (FORTES, 2017) destes indivíduos, aqui entendida como o processo pelo qual nos tornamos indivíduos singulares, que atuam de forma única no mundo, e de seu processo de construção identitária enquanto licenciandos (CUNHA; MOREIRA, 2008; PIMENTA, 1999), 
ainda que exista convergência e semelhança em algumas situações e experiências comuns a um certo grupo de sujeitos. Embora os três entrevistados possuíssem a experiência de estarem na escola pública enquanto estudantes, entende-se que essa não os tornava iguais, pois as experiências se traduzem de forma subjetiva de acordo com quem somos, e isso depende não só das escolas que frequentamos, mas de aspectos familiares, econômicos, etc. Em suma, depende de tudo o que acontece conosco e ao nosso redor. Compreendemos, então, que a identidade enquanto formas de nos inserirmos na sociedade, também está sujeita ao nosso contexto, aos discursos que fazem parte de nossa vida e que nos representam, e, portanto, à linguagem (GEE, 2001).

Essa identidade, que aqui é entendida precisamente como a forma como nos encaixamos em determinados papéis dentro da sociedade, pode se definir tanto por meio da identificação com determinados grupos e comportamentos, quanto por meio da des-identificação (FORTES, 2017), quando nos deparamos com algo ou alguém que está em contradição com quem somos e o que acreditamos enquanto sujeitos. Tanto a primeira quanto a segunda experiência, fazem com que nos posicionemos nos ambientes em que estamos inseridos. Identidade e subjetividade são, portanto, complementares, ainda que a primeira trate da forma como nos consideramos parte de algo, e a segunda, da forma como nos destacamos individualmente apesar disso (FORTES, 2017). Uma precisa da outra para existir.

Compreendemos, assim, que vivemos um constante processo de subjetificação e construção identitária, sendo parte de uma sociedade que se transforma diariamente e que é rica em discursos, letramentos e linguagens. Cunha e Moreira (2008, p. 6) observam que através das ações mediadas pela linguagem "resistências podem ocorrer e propiciar a criação de contradiscursos em que novas posições se definam". O Pibid proporciona ao licenciando situações que o levam a refletir e se questionar a respeito da docência e dos assuntos intrinsecamente humanos que se atrelam a ela, como questões sociais, afetivas, etc. Por isso, ele acaba por também influenciar opiniões e crenças a respeito da educação pública para aqueles que participam do programa, ao mesmo tempo em que influencia a formação da identidade dos sujeitos professores e aprendizes de língua inglesa inseridos naquele contexto. Desse modo, novas identidades são formadas e reconstituídas dentro e fora do Pibid e da universidade.

Os relatos que apresentarei adiante mostram que os três entrevistados da pesquisa tiveram vivências muito diferentes durante o programa, e que a forma como estas foram 
PERcursos Linguísticos • Vitória (ES) •v. 11 •n. 27 • 2021 • ISSN: 2236-2592・

Dossiê: Pibid e RP na formação de professores de letras •

assimiladas por cada um deles também divergiu consideravelmente; o que faz sentido quando se leva em conta a breve discussão sobre identidade e subjetificação apresentada nos parágrafos anteriores.

\section{O impacto do Pibid na relação licenciando x escola}

Uma vez que a intenção do estudo foi compreender de que formas o Pibid influi na formação de futuros professores de língua inglesa, é necessário discutir alguns pontos no que toca o ensino dessa disciplina na escola pública. A disciplina de LI na escola regular carrega uma série de estigmas consigo. Não raramente se ouve comentários sobre a ineficácia desta na escola pública. Fortes (2017, p. 25) observa que essa crença "não vem apenas dos cursinhos de idiomas; é uma ideia que se espalha através de alunos da rede pública e dos próprios professores, baseados em uma série de argumentos".

Tais argumentos derivam de diversos fatores que realmente dificultam um ensino e aprendizado mais significativo do idioma, como por exemplo, a baixa carga horária da disciplina dentro da escola, a aparente descontinuidade dos conteúdos (o que muitas vezes ocorre quando um novo professor assume a turma), a falta de familiaridade de alguns professores com o idioma, entre outros. Nas falas e mitos surgidos a partir desses problemas, nasce o que se conhece como discurso do fracasso (FORTES, 2017). Ou seja, a ideia de que aprender - e, consequentemente, ensinar - inglês dentro da escola pública é praticamente impossível. Esse discurso possui grande força em nossa sociedade, mas o Pibid, ao aproximar o licenciando da realidade da escola pública, permite a desconstrução - ou ao menos o questionamento - dele.

Partindo dessa percepção, a primeira etapa das entrevistas procurou entender se, e de que forma, o programa em questão influenciou a visão dos três entrevistados no que diz respeito à educação de língua inglesa, iniciando pela pergunta 1) Como o Pibid mudou sua compreensão acerca da docência de língua inglesa? Escreva um relato sobre como o Pibid fez isso. Passaremos, nas linhas que seguem, à apresentação e análise das narrativas dos participantes. 
Eu passei a compreender que o cargo/função de professor da escola pública é muito diferente do que eu imaginava antes de passar pela experiência do Pibid. Ao ter contato diretamente com os alunos e constatar que eles estão, na maioria das vezes, motivados e dispostos a aprender, eu mudei a minha percepção sobre o ensino público. Eu sabia que eu não tinha a menor noção de como era dar aula, porque nunca tinha dado uma. Daí eu vi que para mim é difícil, acho que principalmente por causa da minha personalidade. Tem que lidar com gente o tempo inteiro nessa profissão, e eu não sou muito bom lidando com gente. (Pibidiano X)

É difícil falar que a minha compreensão mudou quando antes não tinha muito conhecimento sobre isso. Não sei se foi sorte, mas sempre tive ótimos professores de inglês. No Pibid percebi que o professor estava mais preocupado em passar o conteúdo e terminar o livro do que saber se os alunos estavam aprendendo ou entendendo o que ele dizia. $\mathrm{O}$ que mudou para mim nesse sentido, foi saber que nem todos os professores se preocupam com o que os alunos aprenderam e baseiam seus julgamentos em avaliações, onde muitas vezes os alunos não vão bem. [...] Apesar do percurso ter sido cheio de altos e baixos, foi bom para me mostrar que a docência exige muito mais do que apenas o conhecimento de algum assunto. (Pibidiana $\mathrm{Y}$ )

O primeiro ponto que nos chama atenção nesses dois relatos, é o choque entre expectativa $\mathrm{x}$ realidade que atinge os dois pibidianos. Como observado antes, ambos são exalunos do ensino público, e, ainda assim, seus reencontros com a escola a partir de um novo ponto de vista trouxeram surpresas, estranhamentos, novas percepções, e até mesmo constatações mais pessoais e identitárias, como no caso do pibidiano $\mathrm{X}$ que se deu conta de certa incompatibilidade entre a profissão de professor e sua personalidade, sua identidade e a subjetividade que a constitui. O ponto positivo é que, sendo o Pibid um programa que abrange turmas somente até o quarto período do curso de licenciatura, essas análises pessoais e profissionais podem acontecer ainda no início da graduação, dando ao licenciando a chance de repensar seus conceitos ou mesmo sua escolha de profissão, o que diminui a probabilidade de que este se torne um profissional despreparado ou frustrado no futuro. Para além da profissão, o Pibid faz o bolsista $X$ se confrontar identitariamente, proporcionando-lhe um momento de reflexão sobre si a partir de reflexões e experiências concretas vividas pelo Pibid. A Pibidiana Y, por sua vez, nos leva a pensar em outro aspecto da formação de um professor de Inglês. Ao vivenciar a escola pública com todos os desafios que a instituição oferece, ela acabou por compreender que a docência de LI vai muito além de dominar o idioma em qualquer uma das quatro habilidades: escuta, fala, leitura e escrita. Diferente dos cursos livres, onde o tempo disponível e o domínio do idioma são, em geral, as primeiras exigências para se tornar um instrutor, ser um professor dentro da escola básica traz a necessidade de uma compreensão mais 
crítica daquilo que se ensina e de sua própria identidade, que se forma também a partir das constantes reflexões e desafios da profissão.

A pergunta seguinte 2) Como você se percebe hoje, após a experiência do Pibid, enquanto futuro professor licenciado em língua Inglesa? buscou aprofundar a análise dos pibidianos sobre a profissão docente e como esta pode atuar em sua constituição identitária enquanto professor de língua inglesa, bem como em seu possível retorno para a sala de aula da escola pública, desta vez, assumindo uma nova identidade.

\begin{abstract}
Como tive exemplos não tão bons, hoje eu só quero ser uma professora diferente do que eu percebi nas escolas que fui. Quero ser alguém que não impõe o que você acredita sobre os outros. [...]. Que tenta fazer com que os alunos se engajem com as aulas, e que acredita no potencial que eles têm. (Pibidiana Y)

Após a experiência do Pibid, percebi que infelizmente a docência não é algo que pretendo para a vida toda. Sou alguém que toma muito as dores dos outros e lembro exatamente de cada momento em que um aluno específico me contou os problemas da vida e foi algo que me afetou imensamente. Comecei então a analisar que isso seria algo que aconteceria todo dia no futuro, com 5 turmas com cerca de 30 alunos cada em apenas um turno, e todos eles teriam suas histórias tristes... Eu infelizmente não teria psicológico, pois como mecanismo de defesa, inconscientemente começaria a ser mais distante com os alunos para não sofrer tanto. Tem também o papel da escola, governo e comunidade que não aceitam muitas coisas que queríamos poder ensinar. [...] Então hoje em dia, ser professor requer muita luta, força de vontade e paixão pelo que faz. [...]. Eu acabaria me tornando exatamente todos os professores que sempre critiquei e até hoje critico, e me tornaria uma pessoa angustiada na vida por isso. Então, para poupar tanto a mim quanto a meus possíveis futuros alunos de situações constrangedoras e experiências angustiantes, decidi que não pretendo seguir essa carreira para a vida toda. (Pibidiana Z)
\end{abstract}

É interessante observar como a visão da carreira docente parece estar intrinsecamente ligada ao aspecto afetivo, emocional, dos professores em pré-serviço. Afinal de contas, falamos de subjetividades. Nota-se que a pibidiana Y teve experiências que poderiam desmotivá-la durante o programa, mas pelo contrário, o uso da expressão "quero ser" em sua fala, denota como, ao invés disso, esses episódios apenas reforçaram seu desejo de ser uma boa professora, ou melhor, uma professora diferente daquilo que observou durante a experiência do Pibid. Já no caso da pibidiana Z, é justamente a decisão de não querer ser uma professora fria e distante da realidade de seus alunos que a faz optar por não ser professora "para sempre", uma vez que ela percebe os duros caminhos a que essa escolha poderia levá-la, pessoal e profissionalmente. São dois relatos riquíssimos, que demonstram a mesma preocupação com a qualidade do ensino, 


\title{
PERcursos Linguísticos • Vitória (ES) •v. 11 •n. 27 • 2021 • ISSN: 2236-2592 • \\ Dossiê: Pibid e RP na formação de professores de letras •
}

mas que se dão de formas diferentes em cada licencianda, contribuindo, de formas distintas, para o processo de subjetificação de cada uma. Sobre esse assunto, Fortes (2017) diz que

\begin{abstract}
Biesta e Bingham (2010) também enfatizam que a subjetificação não deve ser entendida como processos de identificação uma vez que a primeira incita a "desidentificação" ou a emancipação por meio de suas formas particulares de "vir ao mundo - uma forma de ser que não se insere e que não faz parte de ordens já existentes". (FORTES, 2017, p. 12).
\end{abstract}

Assim, percebemos que por meio dessa "des-identificação" com o "modelo" de docência encontrado e vivenciado pelo Pibid, ambas as Pibidianas, $\mathrm{Y}$ e Z, constroem suas próprias identidades, que ora se aproximam, ora se afastam do fazer docente em suas diversas manifestações, antes, durante e após a experiência do Pibid. Elas são igualmente capazes de se projetar e pensar no exercício da profissão, o que é muito importante para um aluno de licenciatura. Os autoquestionamentos surgidos a partir de conflitos nas escolas participantes contribuem para a formação de um profissional mais crítico e consciente de duas práticas. Como observa Pimenta (1999, p. 21) “Conhecimento não se reduz à informação. Esta é um primeiro estágio daquele. Conhecer implica um segundo estágio: o de trabalhar com as informações classificando-as, analisando-as e contextualizando-as".

A segunda etapa da qual a autora fala na citação acima, exige do profissional docente e daquele que está em preparo para sê-lo, que exercite seu senso crítico diante das situações que lhe são apresentadas; que saiba filtrar, comparar e questionar o grande fluxo de informações que recebe a todo momento, inclusive dentro da escola. Quando a universidade possibilita a seus alunos de licenciatura um contato maior com o ensino básico, eles têm a chance de relacionar a realidade da educação ao que aprendem em seu curso, e podem levar esse debate para dentro das salas de aula da faculdade, o que enriquece suas formações e influencia seus processos de subjetificação e construção identitária profissional. A resposta da Pibidiana Y à terceira pergunta 3) Como você acredita que a Universidade pode aprender com as experiências do Pibid? é compatível com essa ideia.

Estando no processo de formação, nós como bolsistas deveríamos reportar em forma de relatórios a nossa vivência na escola. Dessa maneira as coordenadoras do programa tinham acesso a esses relatos e acredito que eram capazes de enxergar o que dizíamos de bom ou ruim sobre algumas experiências. Se a universidade conseguir olhar com outros olhos o que escrevemos nos relatos pode aprender quais formas deram certo ou 


\title{
Dossiê: Pibid e RP na formação de professores de letras •
}

não. Não para julgar ou copiar, mas para entender que existe mais de uma forma de se ensinar e aprender. (Pibidiana Y)

Por fim, a última pergunta da primeira etapa da pesquisa foi 4) Qual a sua visão da escola pública depois de ter passado pelo Pibid?

\begin{abstract}
Vejo a escola pública como um local repleto de pessoas interessadas em evoluir. (Pibidiano X)

A minha visão de escola não mudou quase nada. Sempre estudei em escola pública, então eu sei como uma escola pública funciona. Mas olhar para a escola estando de um lado que antes não estava, me fez repensar várias coisas. Para começar percebi que o professor da escola pública pode ser sim um fator desmotivante para o aprendizado dos alunos. [...] Eles estavam sempre usando um recurso repetitivo e desmotivante, fazendo com que os alunos ficassem cada vez mais e mais desinteressados na instituição escola, não vendo a importância dela nas suas vidas. Percebi também que às vezes o corpo pedagógico da escola não se dá bem. Uma das coisas que eu nunca tinha parado para pensar era sobre o que acontecia quando todos os professores se juntavam na sala deles e fechavam as portas durante o recreio. Bom, agora eu sei, e isso me ajudou a olhar de um outro ângulo para o que seriam os professores. Não sei se fui clara, então para esclarecer digo que a minha visão da escola pública hoje, graças ao Pibid, é de que a escola é um lugar onde existe muito mais do que os pais ou os alunos possam ver. A escola não é um lugar perfeito. Os professores não são perfeitos e a desmotivação dos alunos não é sempre causada por eles mesmos. (Pibidiana Y)
\end{abstract}

Há, nessas duas respostas, uma marca da diferença entre as experiências dos dois bolsistas, o que se evidencia ainda mais nas análises da segunda etapa de entrevistas. É importante observar que, embora a pibidiana $X$ relate sua constatação de que o professor da escola pública pode ser desmotivador, minha percepção acerca deste assunto é que qualquer professor pode desmotivar seus alunos - atue ele na escola pública básica, na rede privada de ensino ou mesmo na universidade. O comportamento desmotivador pode estar, acima de tudo, associado ao modo como o professor em questão se relaciona com seu trabalho (e com as condições muitas vezes adversas inerentes a ele) e com os estudantes, e até mesmo com os aspectos pessoais do indivíduo, sendo, portanto, parte da subjetividade de cada docente. Mas nota-se que a experiência docente da pibidiana $\mathrm{Y}$, mais do que fazê-la questionar a forma como via os professores, fez com que ela questionasse a forma como até então via os estudantes, a quem ela até mesmo responsabilizava, em alguns momentos, por eventuais fracassos escolares, 
quando, na verdade, estes são fruto de um sistema muito mais complexo. Collares (1992) observa que existem tanto fatores extraescolares quanto intraescolares que culminam no que se entende como um fracasso. O primeiro caso envolve as condições sócio-históricas dos alunos da escola pública, que, quando precárias, trazem uma série de consequências para o desempenho destes. Já os fatores intraescolares dizem respeito ao currículo, ao trabalho desenvolvido pela gestão e professores, aos mecanismos de avaliação, etc. Citando Mello (1983), ela acrescenta que

\footnotetext{
Nesse sentido, essas condições escolares contribuem para reproduzir a desigualdade social, por meio de um duplo mecanismo: o primeiro é a exclusão dos mais pobres da escola, o segundo, a legitimação dessa exclusão na medida em que o aparecer apenas técnico do modo de operar da escola dissimula seu sentido político. (MELLO, 1983, apud COLLARES, 1992, p. 25).
}

Percebemos que as vivências do Pibid também permitem que os estagiários do programa compreendam melhor os aspectos sociais que permeiam o universo escolar e que possuem enorme peso no desempenho dessa instituição.

\section{Multiletramentos no Pibid Letras-Inglês da Ufes}

Para a última etapa de entrevistas foram elaboradas duas perguntas. Dessa vez, a intenção era debater as práticas de sala de aula dos pibidianos dentro da escola durante sua participação no programa, em momentos nos quais eram solicitados que planejassem e executassem atividades junto aos alunos. Aqui temos em vista a definição de multiletramentos trabalhada por Moura e Rojo (2012, p. 13), que nos dizem que esse conceito trata de dois tipos de multiplicidade: "a multiplicidade cultural das populações, e a multiplicidade semiótica de constituição dos textos por meio dos quais ela se informa e se comunica". Enquanto o primeiro "multi" fala da descentralização da cultura, de como esta não deve mais ser vista como única, mas sim plural, o segundo nos fala da multiplicidade de linguagens e textos em circulação, de maneira impressa, oral, visual, corporal ou mesmo digital. As Orientações Curriculares para o Ensino Médio para o ensino de Língua Estrangeira (OCEM-LE), um dos documentos oficiais da educação brasileira (BRASIL, 2006), incentivam a inserção dos multiletramentos na rotina escola, como observam Duboc e Ferraz (2011, p. 128) ao dizer que "estamos inseridos em um mundo culturalmente organizado por múltiplos sistemas semióticos, sendo necessário ampliar 
as atividades de letramento da letra para os múltiplos letramentos". Como as teorias de Letramentos têm sido amplamente debatidas na graduação de Letras-Inglês da Ufes há alguns anos, as duas perguntas finais foram elaboradas com a finalidade de levantar dados sobre sua presença nas salas de aula do Pibid.

Durante o Pibid 2018-2019, alguns dos bolsistas tiveram a oportunidade de trabalhar os multiletramentos em sala de aula, como por exemplo, analisando com os alunos videoclipes produzidos por imigrantes refugiados, ou mesmo utilizando ferramentas digitais e as linguagens que fazem parte delas para realizar dinâmicas durante a aula. Partindo disso, a primeira pergunta da segunda etapa de entrevistas questionava: 1) Os multiletramentos estiveram presentes nas suas práticas como estagiário do PIBID? Se sim, dê o exemplo de um momento. Os excertos abaixo trazem algumas das respostas.

\begin{abstract}
Sim, houve algumas aulas em que utilizamos alguns recursos diferenciados para a explicação do assunto que estávamos abordando, como por exemplo: jogos educativos envolvendo os alunos e professores, ou então receitas de pratos ou doces com ingredientes que normalmente não seriam aproveitados, com a intenção de ensinar sobre o reaproveitamento de alimentos. (Pibidiano X)

Bom, é até estranho parar para pensar que durante 18 meses não pude de fato ter apoio, por parte do professor, para propor atividades onde os multiletramentos estivessem presentes. Infelizmente posso dizer que eu sentia como se os alunos não tivessem voz ou lugar na sala de aula. Foi frustrante e decepcionante perceber que o mais importante para o professor era terminar o livro e passar o conteúdo. [...] Infelizmente eram apresentados contextos que não condiziam com a realidade dos alunos, e era frustrante observar que eles sabiam disso, mas que o professor parecia não enxergar o que eles diziam. (Pibidiana Y)
\end{abstract}

Fica evidente a disparidade entre o contexto encontrado em uma escola e na outra. Isso também nos leva a pensar nas subjetividades dos próprios professores-supervisores, e na forma como estes se relacionavam com a docência e com os pibidianos com quem conviviam. $\mathrm{O}$ fato de que alguns estagiários tiveram experiências agradáveis enquanto outros passaram por situações complicadas pode soar injusto a princípio, mas na verdade apenas aponta para as infinitas possibilidades de aprendizado real mediadas por um programa como o Pibid, uma vez que a carreira docente não é feita apenas de momentos fáceis. Ambrosetti et al. (2013) observam que 
Entendemos que com um movimento no qual os conhecimentos profissionais vão sendo construídos e reconstruídos nas situações da docência, submetidos à reflexão crítica fundamentada na teorização e alimentada pela experiência, surge também um espaço de construção de um novo conhecimento, produzido nas relações entre instituições e sujeitos, integrando os diferentes saberes que constituem o conhecimento profissional. (AMBROSETTI et al, 2013, p.170).

A fala das autoras reafirma a ideia de que os confrontos que a experiência docente proporciona podem trazer ainda mais conhecimento aos professores, desde que acompanhados de uma atitude reflexiva, questionadora acerca dessas vivências. Ao oferecer aos bolsistas a possibilidade de analisar suas experiências por meio da produção de diários de campo, e dos encontros quinzenais, o Pibid Letras-Inglês da Ufes incentivou tal processo de construção de novos saberes e a análise crítica dos Pibidianos sobre suas ações como participantes do programa.

A última pergunta da segunda etapa de entrevistas visava saber se a prática dos multiletramentos tornara a experiência em sala de aula diferente para os pibidianos e alunos. Entende-se que perspectivas de ensino que valorizam a diversidade são de fato necessárias em nossa sociedade não apenas porque vivemos em um mundo globalizado, mas também porque, quando pensamos no Brasil, por exemplo, estamos falando de uma sociedade extremamente miscigenada e economicamente desigual. Buscar formas de ensinar que acolham a diversidade ao invés de afastá-la é uma maneira de lutar contra a exclusão de grupos marginalizados, mostrando-lhes que a escola também é o lugar deles. Também é uma maneira de mostrar aos educandos que existem diferentes formas de se aprender e de se expressar.

As respostas obtidas para a última questão 2) De que forma a prática dos multiletramentos tornou a experiência em sala de aula - sua, dos alunos - diferente?, apontam para duas direções/dois argumentos: a primeira delas é o quanto a prática dos multiletramentos pode tornar o ambiente escolar produtivo, como evidenciado pela fala do Pibidiano X. Ainda assim, nem todos os professores em serviço têm facilidade ou desejo de adaptar suas práticas, e por isso encontramos situações como a relatada pela Pibidiana $\mathrm{Y}$ em sua fala anterior. A segunda constatação, portanto, é a de que uma prática de ensino repetitiva e sem significado acaba por tornar a sala de aula um ambiente frustrante tanto para os alunos quanto para os próprios professores, além de ser estranha ao mundo "real", fora da escola. As falas apresentam as respostas dos pibidianos à última pergunta do questionário: 


\begin{abstract}
A prática de multiletramentos tornou o aprendizado diferente a partir do momento que os alunos passaram a não encarar a atividade como um "trabalho" a se fazer [...]. Pude perceber que há sim alguma flexibilidade nas salas de aula para que os professores possam implementar atividades mais descontraídas e que entretenham mais tanto os alunos quanto eles mesmos, tornando o aprendizado mais receptivo. (Pibidiano $\mathrm{X}$ )

Ela não tornou. Não tive liberdade para prática dos multiletramentos. Tiveram momentos sim onde elaborei, com outros estagiários, atividades com esse intuito de melhorar, aproximar o convívio e o tempo que passávamos na sala com os alunos, mas essas atividades nunca chegaram a ser feitas, uma vez que o professor não nos permitia fazer algo fora do modelo de aula dele. Isso me fez ver que tipo de profissional eu espero não me tornar. Sei que existe um vácuo entre a formação do professor e a minha, mas isso não impediria nenhuma das partes de entender e aprender um com o outro. O professor não é o único que sabe, o aluno não é o único que aprende. É um processo onde ambos aprendem e ensinam. Por não ter visto esse tipo de interação, eu tenho esperança de que enquanto estiver exercendo a profissão eu não me esqueça disso. (Pibidiana Y)
\end{abstract}

Apesar das dificuldades, podemos perceber que a pibidiana Y continua a demonstrar interesse em seu futuro como professora e pensa na atividade docente de forma crítica, levando em conta o que absorveu de sua experiência no programa. Zeichner (2010) discute a importância desse terceiro espaço de formação, que é compreendido como a prática docente dos licenciandos enquanto ainda estão aprendendo a teoria em seus cursos. De forma geral, essa prática acontece através de projetos e estágios. No caso da pesquisa apresentada neste artigo, ela aconteceu por meio do Pibid, e é possível ver por meio das respostas dos entrevistados que o programa, de fato, trouxe uma nova perspectiva da docência para cada um deles, influenciando até mesmo suas intenções profissionais.

Ao fim da pesquisa, constatou-se que cada um dos pibidianos entrevistados parecia ter escolhido, ainda que momentaneamente, caminhos diferentes. Enquanto Y planejava se tornar professora apesar das dificuldades, $X$ descobriu não se ver exercendo essa função mesmo com sua experiência positiva no Pibid, e $\mathrm{Z}$ decidiu que não seguiria a carreira após se dar conta de que as condições da profissão a levariam a se tornar uma professora aquém de suas expectativas. Compreendemos, assim, que a experiência do Pibid é, como um todo, subjetificadora. As vivências proporcionadas pelo programa contribuem não apenas com a construção identitária dos pibidianos enquanto futuros professores, mas com seu próprio processo de subjetificação pela identificação ou pela des-identificação, especialmente no que os define como indivíduos únicos e plurais. A potência do programa é evidente diante da análise desses relatos. 
PERcursos Linguísticos • Vitória (ES) •v. 11 •n. 27 • 2021 • ISSN: 2236-2592・

Dossiê: Pibid e RP na formação de professores de letras •

\section{Conclusões}

A docência é uma carreira complexa. Ela é feita de uma série de perdas, ganhos e percalços que se apresentam para aqueles que a escolhem ainda durante os primeiros anos de formação. A escolha de permanecer nessa área profissional não é simples, embora às vezes seja uma necessidade imediata. Independente da razão que leva alguém a fazer um curso de licenciatura, o contato com o chão da escola ao longo da graduação é de suma importância, e tem enorme impacto na forma como a profissão de professor é vista e exercida.

Levando isso em conta, o Pibid se reafirma como possível e necessário mediador entre escola e universidade, teoria e prática. Oferecendo aos seus participantes a chance de conectarem os saberes produzidos nessas duas instituições, o programa tem potencial para contribuir com a graduação da licenciatura de Letras-Inglês, e também de incentivar trabalhos e pesquisas como esta, fomentando discussões sobre a própria formação de professores.

Sabemos que a docência é, em si, uma função transformadora pois exige do profissional que a exerce uma incrível capacidade de adaptação, além da disponibilidade de aprender com todos ao seu redor. Se entendemos que o trabalho dos professores é cansativo por diversos motivos, e muitas vezes estes não encontram tempo de qualidade para revisitarem aspectos e teorias importantes de sua formação, o Pibid surge como uma genuína forma de conectá-los de novo ao que aprenderam (ou não) na universidade, pois, assim como a realidade se altera a cada dia, os discursos que circulam na universidade e que formam professores de línguas também têm se alterado. A exemplo disso, vemos uma formação inicial na licenciatura em Letras-Inglês da Ufes cada vez menos estruturalista e mais crítica, pautada em teorias de Letramentos (Multiletramentos) e em visões de língua e linguagem mais fluidas e heterogêneas.

Em suma, conclui-se que o maior contato com a escola durante a formação, oferecido pelo Pibid, é de indiscutível relevância em termos de formação profissional, além de sua relevância nos processos de subjetificação e construção identitária dos futuros professores de Inglês. O programa se revelou, ao longo da pesquisa, como um potente terceiro espaço de formação, como proposto por Zeichner (2010), e as experiências e relatos que se produzem nele podem ser, sem dúvida, uma fonte de estudo para os cursos de licenciatura e aqueles que se 
PERcursos Linguísticos • Vitória (ES) •v. 11 •n. 27 • 2021 • ISSN: 2236-2592・

Dossiê: Pibid e RP na formação de professores de letras •

interessam pelo campo educacional, pois apresentam uma perspectiva simples, e ainda assim, cheia de complexidade, do dia-a-dia da escola; uma perspectiva de quem tem a rica possibilidade de ser, ao mesmo tempo, estudante e professor em pré-serviço.

\section{Referências}

AMBROSETTI, N.B. et al. Contribuições do PIBID para a formação inicial de professores: o olhar dos estudantes. Educação em Perspectiva, Viçosa, v. 4, n. 1, p. 151-174, jan./jun. 2013. BOGDAN, R.; BIKLEN, S.K. Qualitative research for education. Boston: Allyn and Bacon, 1982. 328p.

COLLARES, C.A. Ajudando a desmistificar o fracasso escolar. Série Ideias, São Paulo, n. 6, p. 24-28, 1992.

CUNHA, R; MOREIRA, A. A discussão da Identidade na Formação Docente. Rio de Janeiro: Revista Contemporânea de Educação v.3, n.5. 2008.

DUBOC, A.P.; FERRAZ, D.M. Letramentos críticos e formação de professores de Inglês: currículos e perspectivas em expansão. JORDÃO (org.) Letramentos e Multiletramentos no Ensino de Línguas e Literaturas. Revista X, vol.1, 2011.

FORTES, L. Ser ou não ser: questões sobre subjetividade e o ensino de Inglês na escola pública. 2017. 233 f. Tese (Doutorado em Linguística Aplicada). Departamento de Letras Modernas, Universidade de São Paulo, São Paulo, 2017.

GEE, J.P. Reading as situated language: A sociocognitive perspective. Journal of Adolescent \& Adult Literacy, 44, 714-725. 2001.

PAIVA, V. L. M. O. A identidade do professor de inglês. APLIEMGE: ensino e pesquisa. Uberlândia: APLIEMGE/FAPEMIG, n.1, p. 9-17, 1997.

MOURA, E; ROJO, R. Multiletramentos na escola. São Paulo: Parábola Editorial, 2012.

PIMENTA, S.G. Formação de professores: identidade e saberes da docência. In: PIMENTA, Selma Garrido. (Org). Saberes pedagógicos e atividade docente. São Paulo: Cortez Editora, p. 15 a 34, 1999. 
PERcursos Linguísticos • Vitória (ES) •v. 11 •n. 27 • 2021 • ISSN: 2236-2592 •

Dossiê: Pibid e RP na formação de professores de letras •

ZEICHNER, K. Repensando as conexões entre a formação na universidade e as experiências de campo na formação de professores em faculdades e universidades. Educação, Santa Maria, v. 35, n. 3, p. 479-504, set./dez. 2010.

UNIVERSIDADE FEDERAL DO ESPÍRITO SANTO, Projeto Pedagógico do Curso de Licenciatura em Língua e Literatura Inglesa, Vitória, 2006. 